\title{
FAMÍLIAS INCESTUAIS
}

\author{
Belinda Mandelbaum*
}

\section{Resumo}

A autora se propóe examinar uma configuração familiar que nomeia, a partir da conceituação de Racamier (1995), de família incestual e que se caracteriza por relaçôes internas que negam as diferenças entre os sexos e entre as geraçôes. Propóe que esta configuração ressoa, no interior da família, aspectos da vida social na contemporaneidade, tais como descritos por diversos autores, dentre eles Baudrillard (2009). Apresenta um caso clínico que serve para ilustrar aspectos do funcionamento psíquico de uma família incestual.

Palavras-chave: família incestual; configuração familiar; indiferenciação.

\section{Abstract \\ INCESTUAL FAMILIES}

This article focuses on a family configuration called, according to Racamier's conception (1995), incestual family which is characterized by the denial of the differences of sexes and generations. It is understood that this family configuration reflects elements of contemporary social life as described by Baudrillard (2009), among others authors. A clinical case is presented focusing on those issues.

Keywords: incestual family; family configuration; indiscrimination.

Há um padrão de convivência familiar que, ainda que não exclusivo da contemporaneidade, contém elementos que permitem fazer da família uma espécie de lócus de observação da vida social em nossos tempos. Muito se tem dito sobre os novos arranjos familiares, sobre as transformaçóes pelas quais passa a família hoje - a incidência crescente de famílias monoparentais, com número menor de filhos, famílias mosaico, homoparentais, ou mesmo sobre a reprodução dos filhos por técnicas assistidas de fertilização ${ }^{1}$. Autores nos diversos campos nos

\footnotetext{
* Instituto de Psicologia, USP, São Paulo, Brasil. E-mail: belmande@usp.br.
} 
quais a família é estudada - a Sociologia, a Antropologia, a História, a Psicologia e a Psicanálise - perguntam-se sobre o significado dessas transformaçóes, suas causas e seu impacto no desenvolvimento dos seres humanos.

Mas não é das transformações nos arranjos e composiçôes das famílias na contemporaneidade que desejo tratar aqui. Trata-se de algo mais interno à dinâmica familiar - os modos como se dão, em diversas famílias, as formas de relaçáo entre os sexos e entre as geraçóes. Sugiro que estas formas de relação operam em ressonância com certos padróes de existência que diversos autores, dentre eles Baudrillard (2009), têm apontado como característicos da contemporaneidade. São padróes relacionais que se encontram em famílias independentemente de seu arranjo ou composição, inclusive também em arranjos nucleares tradicionais, ou seja, naqueles compostos por pai, mãe e filhos que habitam uma residência independente, com papéis socialmente definidos para cada um deles. Estão presentes em todos os grupos sociais, atravessando categorias de renda, escolaridade, cor de pele etc.

O psicanalista francês Paul-Claude Racamier (1995) nomeou as famílias que tenho em mente de incestuais. Nelas pode não haver o incesto consumado ou uma atividade sexual explícita entre pais e filhos, mas há, operando continuamente, uma atmosfera de sedução e trocas erotizadas entre membros de diferentes geraçóes que envolvem um transbordamento da atividade sexual para além dos limites da intimidade, tornando todas as áreas da vida familiar, por assim dizer, sexualizadas. Racamier (1998, p. 147) definiu o incestual como "aquilo que, na vida psíquica individual e familiar, leva a marca do incesto não fantasiado, sem que sejam necessariamente consumadas as formas genitais" ${ }^{2}$. $\mathrm{O}$ incestual estaria entre o incesto fantasiado e o incesto genitalmente consumado, sendo característico de formaçóes psíquicas de natureza perversa, nas quais a sombra do incesto aproxima-se de forma prevalente e concreta. Num artigo sobre a noção de incestual em Racamier, Jaroslavsky (2010) diz que esta

não tem a ver com a via do desejo, da fantasia, não toma a via do símbolo [...] É da ordem da ação. O registro do incestual funciona fora da rede intrapsíquica e intrafamiliar de fantasias e representaçôes. $\mathrm{O}$ incestual não se imagina, não se representa nem se fantasmatiza, não se simboliza (Jaroslavsky, 2010).

O incestual opera, portanto, em trocas entre os membros da família que envolvem ações concretas e objetos que funcionam como equivalentes da atividade incestuosa, sejam objetos corporais, roupas íntimas ou presentes - todos estes 
erotizados e alvos de manipulaçôes que fazem parte, segundo Jaroslavsky (2010), de uma espécie de comércio erógeno que circula no interior do grupo familiar como substituto disfarçado do ato incestuoso.

Mas, ainda que a incestualidade seja característica de formações individuais ou familiares perversas, sugiro que não restrinjamos este conceito exclusivamente a uma patologia psíquica, uma vez que os padróes que estamos procurando descrever parecem ressoar, no interior da família, formas de ser e de se relacionar próprias da contemporaneidade. Nessa configuração psíquica se faz presente - para além da complexa trama dos desejos suscitados na convivência familiar - toda a ambientação cultural e ideológica, os padrões promovidos pela mídia, a publicidade e a moda, que penetram cada interstício da vida em família, como Adorno e Horkheimer (1978) já apontavam em meados do século passado.

O sociólogo francês Jean Baudrillard (2009) detectou um extravasamento do sexual, uma erogenização das relaçôes sociais como característica da cultura ocidental nas últimas décadas, em especial a partir dos anos 60 do século XX. Um dos elementos dominantes deste estado de coisas é a ruptura das diferenças entre os sexos e entre as geraçóes - uma espécie de padrão intercambiável dos modos de ser, vestir-se, consumir, com importantes ligaçóes com a indiscriminação entre o real e o virtual favorecida pela Internet, produzindo como resultado, segundo ele, identidades sexuais confusas. Numa leitura que podemos aproximar da que Racamier (1995) fez do incestual, Baudrillard diz:

A possibilidade de metáfora está desaparecendo em todas as esferas [...]. A substituição é possível entre uma esfera e qualquer outra. Há uma total confusão de tipos. $\mathrm{O}$ sexo não está mais localizado no próprio sexo, mas em algum outro lugar - em todo lugar, de fato. Há um desaparecimento da diferença sexual e, portanto, da sexualidade per se [...]. Estamos certamente em transição para um estado de coisas transexual que tem tudo a ver com uma confusão e uma promiscuidade que abrem a porta para uma indiferença virtual (em todos os sentidos da palavra) no terreno da sexualidade (Baudrillard, 2009, p. 8).

Nestas condiçóes, todos os modos de ser e de viver tornam-se virtualmente possíveis. Toda identidade é vivida como instável, temporária, ou, nos termos de Butler (1997), como uma performatização contingente dos modos de ser, na dependência dos diferentes contextos nos quais nos movemos. Transitamos hoje entre diversas representaçóes de nós mesmos e de outros. Nas palavras de Bau- 
drillard (2009, p. 24), "ser si mesmo tornou-se uma performance transitória sem sequelas, um maneirismo desabusado num mundo sem maneiras de ser".

Propomos que esta fluidez identitária manifesta-se, em diversas famílias, em uma espécie de indiscriminaçâo entre os lugares de cada um: do ponto de vista psíquico, quem é pai e quem é mãe? Quem é filho e quem é filha? Quem forma casal com quem? É claro que uma leitura superficial, feita a partir dos aspectos mais manifestos do grupo familiar, poderia com facilidade apontar quem é quem. Mas do ponto de vista das relaçóes internas, das experiências subjetivas e das condutas dos membros da família uns com os outros, todas essas posiçóes parecem ser continuamente intercambiadas, numa dança de lugares que não permite uma identificação estável do que é ser adulto ou ser criança, pai ou filho, homem ou mulher.

São estas algumas das características que encontramos no que Racamier (1995) chamou de família incestual, na qual as diferenças e limites são abolidos, a intimidade de cada um dos membros pode ser devassada e há um trânsito intenso entre os espaços íntimos que flui do mesmo modo que o trânsito das identidades e das posições no interior do grupo. Muitas vezes, como já assinalamos, não se encontram nessas famílias evidências de incesto consumado, mas há algo que corresponde a uma confusão erótica, com seduçóes, exposição contínua dos corpos, troca de afagos e presentes, borrando cotidianamente as diferenças sexuais e geracionais.

\section{Caso clínico}

Tenho em mente, a fim de ilustrar o que estou sugerindo, uma família composta pelos pais, Rosana e Fábio, ambos em torno dos 45 anos, e dois filhos, uma menina de nove anos, Júlia, e um menino de cinco, Tomás. Embora a avó paterna, viúva, não viva na casa, ela participa sempre das atividades de lazer da família, bem como contribui financeiramente de diversas formas para a manutençáo do status quo familiar. O pai trabalha com seu único irmão, mais velho do que ele, num negócio deixado pelo avô paterno, cujos rendimentos são divididos entre os três - avó, pai e irmão do pai. Mas dizer que os rendimentos são divididos não quer dizer, neste caso, dividir por igual: o irmáo mais velho, com forte ascendência sobre Fábio, tem o controle da empresa, enquanto o trabalho deste parece ser apenas pro forma. Fábio é excluído, segundo Rosana, das decisões e do gerenciamento do capital. Ele parece permanecer eternamente como o garoto caçula de sua família de origem - um meninão incapaz, apesar da idade que tem, de gerir sua vida. Como parte desta configuração, ele se mantém dependente das benesses de sua mãe, que paga o carro novo, o motorista da família, o apartamento na praia, etc. 
Rosana é filha única de um casal já falecido. Perdeu o pai alguns meses após o nascimento do filho menor e a mãe três anos depois. Foi ela quem cuidou de ambos no fim da vida, dividindo-se entre os hospitais e os filhos ainda pequenos. Relata ter sido sempre tratada como uma princesa pelos pais e chora ainda desesperada a falta deles. Herdou o negócio da família e teve muitas dificuldades na gestão, terminando em dívidas e processos judiciais que, para serem resolvidos, demandaram o aporte financeiro da família de Fábio, de cujas decisões e benesses ela ficava também dependente.

Eles me foram encaminhados para terapia de casal pela escola das crianças. Ao me contatar, a mãe telefonou algumas vezes seguidas, de um dia para o outro, deixando recados urgentes e desesperados antes que eu pudesse retornar.

Fico impactada ao vê-los pela primeira vez: Rosana é uma mulher pequena e magra, tipo mignon, vestida como uma Barbie, com os olhos azuis vidrados, como se, ao invés de uma pessoa, eu estivesse diante de uma boneca artificial. Ele, bem maior do que ela, é gordo e estabanado. Para o nosso primeiro encontro ele trouxe, escrita em folha sulfite desdobrada a minha frente, uma lista na qual arrolara características de Rosana que a definiam como "histriônica", segundo consulta que ele fizera ao Google. Chamou-me muito a atenção a letra com a qual essas palavras estavam escritas, vista por mim a certa distância: eram enormes garranchos incompreensíveis riscados com força no papel. Enquanto ele lia a lista, ela permanecia quieta, imóvel, petrificada. Em seguida ela lhe pediu a palavra, não fez menção alguma à lista que ele acabara de ler, e a conversa que se seguiu era uma tentativa de se apresentarem, mas sempre na toada do ataque e defesa, os dois disputando a palavra com um "você já falou, agora é a minha vez", aparentemente sem se escutarem. Ela se mostrava mais interessada na terapia de casal, ele dizia que era ela quem precisava de tratamento, mas cedia a uma imposição vinda de fora, da escola. Ela associava começar um trabalho terapêutico com vir a ter a ajuda de uma super nanny, que visse tudo o que se passava na casa deles.

Combinamos sessões semanais. Os primeiros encontros foram marcados por um estado geral de confusão e histrionice. Minha atenção era continuamente atraída - invadida, eu diria - por uma pletora de objetos de consumo da moda: vestes de cores berrantes, nomes de grifes nas roupas e acessórios, os dois com Blackberries que seguravam na mão o tempo todo, o que os levava a interromper a sessão para atender. A linguagem era pontilhada de termos retirados da Internet e de programas de TV: o "diagnóstico" que ele dera a ela - histriônica - saíra do Google, a solução que ela dava à família era a super nanny, derivada da TV. Muitos meios de comunicação, os aparelhos todos ligados, mas eles não se escutavam. 
Após a terceira sessão, recebi um telefonema da orientadora da escola dizendo-me ter algo importante para me contar. Assinalei-lhe já estar trabalhando com o casal e preferir ater-me ao que eles dissessem, mas uma urgência em sua voz me levou a perguntar se havia algo que ela considerava imprescindível que eu soubesse. Ela confirmou dizendo que profissionais da escola suspeitavam fortemente de que o pai estivesse abusando sexualmente do filho. Tomás fizera desenhos nos quais um menino e o pai estão envolvidos em atividade de "chupar pinto", como ele disse. Diante da indagação da professora, ele relatou que o fato ocorrera no dia anterior. A orientadora optara por não chamar os pais, em suas palavras "porque são tão doentes que não há com quem falar”. Em vez disto, a própria escola acionou um processo de avaliação que envolveu uma psicóloga e o neurologista do menino, que já lhe havia dado o diagnóstico de retardo geral do desenvolvimento e déficit de atenção, medicando-o com Ritalina. Segundo a orientadora, os dois profissionais confirmaram as suspeitas de abuso sexual. A escola em seguida convocou o tio - o irmão mais velho do pai - para comunicar o ocorrido e, seguindo determinações legais, denunciou o caso à Justiça. No momento em que a orientadora conversava comigo, o casal aparentemente não estava a par de toda esta movimentação. Uma semana após a denúncia ter sido feita à Promotoria Pública, a escola ainda aguardava, segundo a orientadora, "o momento certo" para falar com os pais.

Optei por não introduzir, na sessão seguinte ao telefonema, as informaçóes que recebera, uma vez que considerei que caberia à escola informar aos pais. Minha atitude era de espera em relação ao que pudesse emergir do casal. Não houve na sessão qualquer sinal de que eles tivessem sido comunicados do que acontecera na escola. A conversa correu na toada conhecida de queixas mútuas em torno da grande dificuldade que sentiam no trato com as crianças, em especial para impor limites ao filho.

Uma semana depois, eles chegaram transtornados à sessão: tinham sido comunicados pela escola do que Tomás expusera ali, mas negavam terminantemente o abuso, centrando-se em detalhes do episódio que o menino narrara à professora. No dia anterior ao desenho, o pai tomara banho com ele numa banheira jacuzzi, em casa. A mãe presenciara o banho, disse que na sua frente nada ocorrera, mas que houve um momento em que teve que sair para atender ao telefone e não podia afirmar se aí ocorrera alguma coisa entre eles. $\mathrm{O}$ pai negava. $\mathrm{O}$ casal então passou a acusar a escola, sugerindo que a professora que acompanhava o menino mais de perto, em atividades de reforço, o teria estimulado, com perguntas, a dizer coisas desse tipo. Eles não entendiam por que a escola os perseguia desta forma. Contaram também que recentemente tinham escutado um caso de abuso sexual numa família conhecida, e que Tomás estava com eles quando o caso lhes fora contado. Perguntavam-se entáo se o menino teria fantasiado o episódio com o pai a partir do que escutara. 
Foi acordado entre o tio e a Justiça que as crianças mudariam temporariamente para a casa dele a fim de evitar o risco da institucionalização delas. Em seguida psicólogos peritos e uma assistente social fizeram um diagnóstico da família - pai, mãe e filhos -, avaliando cada um em separado. Todos receberam indicação de terapia individual. O tio assumiu o gerenciamento dos diversos atendimentos e compareceu à sessáo seguinte com o casal para discutir comigo o encaminhamento da terapia. Na verdade, fui surpreendida pela presença dele na sala de espera, mas, dada a excepcionalidade da situação e o fato de que todo o trabalho de atendimento da família necessitava ser repensado naquele momento - cabendo a ele o papel de gestor do processo -, concordei em receber os três. Conversamos sobre o encaminhamento da terapia nesse novo contexto. $\mathrm{O}$ casal mostrava-se subserviente ao tio, que tomou a palavra de modo contido, racional e ponderado. Reiterou que os peritos determinaram terapias individuais e que, diante do excesso de atendimentos dali em diante, eles consideravam a possibilidade de suspender por um tempo o atendimento do casal, para retomá-lo quando os trabalhos individuais estivessem mais avançados. Ele disse também, com a concordância explícita do casal, que gostaria que eu continuasse como terapeuta na família, perguntando-me então se eu concordaria em acompanhar nesse momento um dos dois. O casal já tinha conversado sobre isto e ela expressou que gostaria de continuar comigo, pela confiança que sentira em nosso trabalho inicial. Eu reafirmei a importância da continuidade do trabalho com o casal, mas reconheci também a necessidade que tinham de cumprir as determinaçóes judiciais e o excesso de terapias que isto representava para a família. Ressaltei também a importância, naquele momento, do vínculo de confiança que tinham estabelecido comigo. Em função de tudo isto, acolhi a decisão deles de ver só a ela dali em diante, duas vezes por semana.

Os primeiros meses da terapia de Rosana foram tomados por intensa angústia em relação à separação dos filhos. Era uma angústia entremeada de ódio, em particular em relação à escola, pela maneira como procederam, por não terem falado logo de início com os pais, e por fortes suspeitas suas de que as fantasias de abuso sexual teriam sido inculcadas pela professora no menino. O fato é que nunca se teve evidência explícita do abuso, fosse na terapia ou no que ela me relatava das investigaçóes judiciais, embora tenham emergido durante as sessões com ela evidências de um padrão de relação entre o pai e o filho que envolvia uma espécie de cumplicidade erótica. Ela me contava, por exemplo, que o pai dava "beijinhos" na boca do menino e que, quando ela lhe dizia que isto era inadequado, ele contestava dizendo que "na Rússia os homens se beijam na boca". Invariavelmente, o pai entrava em casa à noite, depois do trabalho, trazendo presentes para o filho 
e, quando ela lhe abria a porta, ele passava reto, um tanto siderado, de braços estendidos para dar os presentes e pegar o menino no colo. Os beijinhos ocorriam com o menino deitado em cima dele, brincando em sua larga barriga. Rosana me relatava também que o pai buscava dar carinhos e beijinhos na filha, mas que esta o rechaçava com expressóes de asco.

Todos estes acontecimentos, culminando na saída das crianças de casa, geraram uma reorganização, como não poderia deixar de ser, de toda a dinâmica familiar. Havia até então uma relação intensa, corporal, permeada por presentes, da qual participava também a avó paterna, com seduçóes contínuas na forma de recompensas concretas a qualquer frustração, tendo como alvo principalmente o menino, o "reizinho" do papai e da vovó. Um dado importante é que o menino levava o nome do avô paterno, falecido antes de seu nascimento. Da mélange erótica entre filho, pai e avó a mãe era excluída. Rosana queixava-se de ter sido continuamente desautorizada na frente do filho e responsabilizada por tudo o que dava errado em casa. A menina, por sua vez, parecia manter-se apartada de tudo isto, buscando fora de casa e pela Internet amizades com crianças de sua idade. Além de evitar o contato com o pai, tinha brigas frequentes com o irmão, no mais das vezes envolvendo violência física. Quando a família viajava, a avó costumava dormir numa cama de casal com os netos, em geral de camisola e sem calcinha. Rosana contava que, durante a noite, a camisola da avó subia e ela ficava praticamente nua na cama com as crianças.

Com a explosão dos acontecimentos na escola, tudo isto mudou. O pai sentiu-se intensamente ameaçado, ficou sob a suspeita de todos os envolvidos, tinha vergonha de encontrar pessoas que ele imaginava que pudessem saber do ocorrido - como outros pais da escola - e recorreu desesperadamente à proteçáo e ao reasseguramento da esposa. Agora ela era a figura forte, que tinha que cuidar do marido/menininho indefeso. Rosana não deixou de viver a situação como uma vitória pessoal, ganhando agora o seu lugar à frente do cenário familiar. Passou a ditar as regras, impondo disciplina férrea em casa. Diante da fragilização do marido, ela se viu forte inclusive para demandar mais ajuda financeira, e ele também nisto passou a acatá-la. Por outro lado, ela aprofundava, através do dinheiro, sua dependência dele e a possibilidade, por exemplo, de separar-se para ficar com os filhos era para ela impensável. Ela reafirmava sempre - mesmo em momentos de desespero e com suspeitas do marido - o seu amor por ele e o seu desejo de ver a família reunida o mais brevemente possível, o que veio a acontecer oito meses depois da saída das crianças de casa. O juiz determinou como condição para o retorno delas que todos seguissem suas psicoterapias e a nossa era parte desta determinação judicial. 
Durante as sessóes com Rosana, eu me via na maior parte do tempo escutando em silêncio um desespero carregado de lágrimas e de pedidos de ajuda concreta. Ela pedia orientaçóes sobre o que fazer, que eu falasse com os terapeutas do marido e dos filhos, que escrevesse cartas para o juiz assegurando que ela estava em tratamento, para acelerar a volta das crianças para casa. Eu tentava falar com ela sobre o sentido de seus pedidos, ao mesmo tempo compreendendo o desespero e a urgência, mas buscando manter-me como alguém que garantisse um espaço confiável no qual ela pudesse expressar seus sentimentos e pensamentos. Ela tendia a compreender e concordar com o que eu dizia, transmitindo um reconhecimento genuíno da importância das sessóes como um espaço para ela. Certo dia em que ela mais uma vez me indagava sobre o que fazer, eu disse após insistências desesperadas que de algum modo ela me pressionava a fazer algo para o qual eu não estava apta, que eu não tinha a resposta que ela me pedia, e liguei estas suas demandas à situação de abuso. Falei que, tal como me fazia sentir ali, eu imaginava que ela muitas vezes se sentia pressionada a fazer coisas que a contrariavam, e talvez estivesse me testando para ver como lido em situaçóes deste tipo. $\mathrm{O}$ que falei pareceu fazer sentido naquele momento e ela passou a relatar como o marido, em situaçóes de lazer, pressionava os filhos a atividades que ele - mas não eles - estava a fim de fazer. Este era um padrão da atividade familiar.

Após aproximadamente dez meses de atendimento, vejo-a menos artificial nos seus modos de ser. Sua apresentação é a mesma, com um excesso de objetos e grifes, mas o olhar vitrificado e certos maneirismos deram lugar a um modo de ser mais pessoal e humanizado. Ela se mostrava inteligente e captava reflexivamente o que eu dizia, embora suas falas seguissem como relatos detalhados e concretos do dia-a-dia, em que parecia estar sempre em questão a capacidade do casal para permanecer com os filhos e a ameaça de perdê-los definitivamente. Após a volta das crianças, passou a relatar cenas cada vez mais frequentes de violência entre elas e o pai, em especial provocaçóes por parte do menino, que o xingava e nele batia. $\mathrm{O}$ pai tendia a perder o controle e revidar com violência, mas começou a pedir que Rosana e a filha o ajudassem, afastando o menino dele nesses momentos.

\section{Consideraçóes finais}

Como relatei acima, o abuso sexual nunca foi comprovado e por isto as crianças puderam voltar para casa. No entanto, considero importante chamar a atenção para padróes de conduta e relação que parecem construir o modus vivendi de uma família que se poderia chamar de incestual. É característico destes padróes 
que as comunicaçóes se deem menos por palavras e mais por coisas - o casal tinha muita dificuldade para conversar e as palavras serviam mais como instrumentos de ataque e defesa, ou seja, as próprias palavras eram usadas como coisas. O modo de se apresentarem, os presentes cotidianos para o filho, a erotização das trocas, tudo parecia servir ao propósito de manutenção de uma excitação contínua, de uma relação de sedução narcisista que perdurava no tempo.

Outro aspecto próprio desta configuração é a negação da diferença entre as geraçôes - a avó dormia com os netos, numa situação em que ostensivamente havia um apelo sexual; o pai entrava na banheira com o filho, trocavam afagos e beijinhos. Nestas trocas eróticas, todos se equiparavam, impedindo assim o desenvolvimento e a travessia edípica. A idade, o sexo e o lugar de cada um na cadeia geracional pareciam não ser levados em consideração como limites que desenhassem os intercâmbios no interior da família. Estes padrôes pareciam em princípio transitar e ser impostos pela família paterna, mais especificamente nas relaçóes entre a avó, o pai e o filho. Rosana por um lado tentava sem sucesso romper estes padróes e, por outro, via-se dependente das benesses financeiras e do padrão de consumo da família. Como vimos nas sessôes, sua forma de comunicação também tinha um caráter concreto, com as palavras exercendo a função de mobilizar atuaçóes minhas - que eu também fizesse coisas, como escrever cartas ao juiz. $\mathrm{O}$ mesmo ocorria nas atividades nas quais a família estava reunida, quando todos deviam atuar segundo a imposiçáo dos desejos do pai ou da avó. A menina era quem procurava afastar-se, na medida de suas possibilidades, do contato com estas imposiçóes. Coube à Justiça a função, como agente externo à família, de impor limites ao extravasamento sexual.

Pierre Benghozi (2010) sugere que há, em configurações familiares deste tipo, ataques aos vínculos de aliança - ao casal parental - e de filiação, sendo estes vínculos substituídos por uma espécie de clã horizontal a que todos estão submetidos. Mas não devemos pensar que, por ser horizontal, este clã não tenha um líder. No caso que relatamos aqui, parece que o casal composto por pai e avó paterna exerce um domínio que tem como objetivo a satisfação de necessidades narcisistas e como regra o direito ao corpo da criança para sua própria fruição. Levantamos a hipótese de que o avô paterno, já falecido, não tenha favorecido o corte na relação entre Fábio e sua mãe, permanecendo ele como um filho eterno, infantil e dependente, incapaz por sua vez de exercer a função paterna em relação ao próprio filho. A própria avó parece não ter dentro de si estabelecida uma função paterna que lhe permita exercer alguma interdição na relaçáo com o filho e os netos. Cada um a seu modo é membro do pacto - a mãe anulada em sua voz, dependente das benesses do marido e da sogra, a filha distante e um tanto isolada 
em casa, o filho em cumplicidade erótica com o pai, a avó mantendo o filho infantilizado e fazendo dos netos os alvos de suas seduçóes.

Frequentemente as instituições jurídicas veem-se diante de casos deste tipo e não encontram evidências, como é o caso aqui, do abuso sexual consumado. As famílias incestuais, como a que procurei abordar aqui, devem fazer com que os profissionais, tanto do campo jurídico quanto da Saúde Mental, repensem a própria concepçáo de abuso sexual com que operam, uma vez que, ainda que não haja evidências de incesto consumado, há importantes efeitos traumáticos nas crianças cujo desenvolvimento se faz em famílias nas quais predominam estes padróes de trocas. Neste caso específico, a ausência das evidências "inocentou" a família. Contudo, a atenção às configuraçóes familiares incestuais permite aprofundar a observação, em nível jurídico e psicológico, de diversos casos em que o desenvolvimento das crianças se faz no interior de estruturas de relação pautadas pela erotização contínua, por ataques aos vínculos de filiação e pela negação das diferenças entre os sexos e entre as geraçóes. O debate contemporâneo em torno do tema deve permitir que tais acontecimentos, vividos muitas vezes no interior de grupos familiares fechados em si mesmos, possam vir à luz. Este debate, a nosso ver, deve também incluir uma reflexão que transcende os limites dos grupos familiares para tratar daquilo de que fala Baudrillard (2009), ou seja, de como hoje somos todos, crianças e adultos, partícipes de uma sociedade que estimula incessantemente, através do consumo, da mídia, dos padróes estéticos que impóe, uma erotização das relaçóes, uma atmosfera contínua de sedução que cultua o narcisismo de cada um e dificulta o reconhecimento das diferenças sexuais e geracionais. É esta atmosfera que envolve e penetra cada interstício de toda vida familiar.

\section{Referências}

Adorno, T. \& Horkheimer, M. (1978). Família. In: T. Adorno \& M. Horkheimer (Orgs.) Temas básicos da sociologia (pp. 132-147). São Paulo: Cultrix (Trabalho original publicado em 1956).

Baudrillard, J. (2009). Transparency of evil. Londres: Verso.

Benghozi, P. (2010). Engana o amor: das transaçóes familiares incestuosas à remalhagem dos vínculos genealógicos. In: P. Benghozi. Malhagem, filiação e afiliação (pp. 141-156). São Paulo: Vetor (Trabalho original publicado em 1997).

Berquó, E. (2000). Arranjos familiares no Brasil. In: L. M. Schwartz (Org.). História da vida privada no Brasil, v. 4 (pp. 411-436). São Paulo: Companhia das Letras. 
Butler, J. (1997). Excitable speech: a politics of the performative. Londres: Routledge.

Jaroslavsky, E, A. (2010). Incestual - Jean-Claude Racamier. Psicoanálisis \& Intersubjetividad, 5. Recuperado em 03 dezembro, 2010, de <www.psicoanalisiseintersubjetividad.com/website/articulop. asp? $\mathrm{id}=234 \&$ idioma $=$ \&idd $=5>$.

Prost, A. \& Vincent, G. (Orgs.). (1991). História da vida privada, vol. 5. In: P. Ariès \& G. Duby (Orgs.). Coleção história da vida privada. São Paulo: Companhia das Letras.

Racamier P.-C. (1995). L'inceste et l'incestuel. Paris: Les Éditions du Collège.

Racamier P.-C. (1998). Incestuel. Vocabulaire de psychanalyse groupale et familiale, tomo I. Paris: Editions du Collège de Psychanalyse Groupale et Familiale.

\section{Notas}

1 A coleção História da vida privada, organizada por Philippe Ariès et al. (1991), traça o percurso de transformaçôes da família no mundo ocidental, desde a Idade Média até nossos dias.

2 As citaçôes utilizadas no texto são de nossa tradução.

Recebido em 24 de outubro de 2011 Aceito para publicação em 15 de março de 2012 